\title{
Commercial equine embryo transfer in the United States
}

\author{
Patrick M. McCue ${ }^{\text {land Mats H. T. Troedsson }}{ }^{2}$ \\ Department of Clinical Sciences, College of Veterinary Medicine and Biomedical Sciences, Colorado State University, Ft. Collins ${ }^{1}$ and \\ Department of Large Animal Clinical Sciences, College of Veterinary Medicine, University of Florida, Gainesville ${ }^{2}$
}

\begin{abstract}
Summary
The basic aspects of embryo transfer in the mare have not changed in several decades. Embryo recovery is usually attempted 7 or 8 days after ovulation and recovered embryos are preferably transferred into a recipient that ovulated 1-2 days after the donor mare. Embryo transfer continues to be a common technique to enhance reproduction in subfertile and performance mares in many breeds. Alterations in breed regulations and the ability to superovulate donor mares have significantly changed the equine embryo transfer industry over the past year. The objective of this review is to provide an update on recent alterations in techniques or industry trends as it relates to embryo transfer in the United States.
\end{abstract}

Keywords: Embryo transfer, USA, technique, equine

\section{Kommerziell durchgeführter equiner Embryotransfer in den USA}

Die Grundsätze des Embryotransfers bei der Stute haben sich während der letzten Jahrzehnte nicht geändert. Die Embryogewinnung wird üblicherweise sieben oder acht Tage post ovulationem versucht und die gewonnenen Embryonen werden in eine Empfängerstute transferiert, die ein bis zwei Tage nach der Spenderstute ovuliert hat. Der Embryotransfer stellt immer noch eine übliche Methode dar, mit der die Reproduktionsaussichten bei subfertilen und Sportstuten zahlreicher Rassen verbessert werden können. Veränderungen in der Zuchtregulation und die Fähigkeit eine Superovulation bei den Spenderstuten zu induzieren hatten in den letzten Jahren großen Einfluß auf die Durchführung des equinen Embryotransfers. Mit diesem Übersichtsartikel sollen aktuelle technische Entwicklungen und industrielle Trends im Zusammenhang mit dem Embryotransfer in den USA vorgestellt werden.

Schlüsselwörter: Reproduktion, Embryotransfer, USA, Technik

\section{Introduction}

The use of embryo transfer (ET) in the equine breeding industry in the United States increased dramatically in 2003 due to changes in breed registry regulations. As a consequence of a lawsuit settled in 2002, the American Quarter Horse Association (AQHA) eliminated the restriction on the number of foals that could be registered to a given mare in a single year. Previously, the AQHA would allow the registration of only one foal per mare per year. In order to bypass this restriction, many mare owners would breed a Quarter Horse mare to a Quarter Horse stallion and perform an ET into a recipient mare. The donor mare was often bred back to an American Paint Horse stallion and allowed to carry to term. In this scenario the foal could be registered with the American Paint Horse Association. Alternatively, the mare could be bred back to another Quarter Horse stallion for either ET or to carry her own pregnancy. The second QH-QH foal would not qualify for registration with the AQHA. Instead the foals were bloodtyped and sold as "DNA" horses, implying that the parentage had been confirmed, but the horse was ineligible for registration. A majority of the ET work was performed in 'cutting horse' type Quarter Horse mares, since the National Cutting Horse Association did not require horses to be registered with a specific breed association to perform.

The American Paint Horse Association and the Arabian Horse Registry of America subsequently followed the lead of the AQHA to not limit the number of foals registered to a specific mare during one season. The American Saddlebred Association has continued to limit the number of foals registered to a single mare in one year to four. The American Morgan
Horse Association has never had a limit on the number of foals that could be registered to one mare in a single year. There is ongoing debate within breed associations as to the effect of unlimited embryo transfer on the economics, genetics and politics of the horse industry, as well as the reproductive health of the donor mare. The changes in breed registry regulations will certainly allow for a greater impact of genetics from the dam as compared to past years. However, it hardly compares with the changes that occurred when the use of artificial insemination allowed for a tremendous increase in the number of mares bred to an individual stallion.

There are more than 3.000.000 registered Quarter Horses in the United States and Canada, with over 150.000 new registries recorded in 2001 . Of these new registries, over 400 were registered as embryo transfer offsprings. As a consequence of the breed registry rule changes, the number of ET performed in the United States increased greatly in 2003. The number of clinics providing ET services increased as did the number of ET 'recipient stations' throughout the country. The cost of ET was considered to be justified by owners if the value of the newborn foal was approximately $\$ 10.000$ or greater. The cost of ET in the United States ranges from $\$ 3.000$ to 6.000 per pregnancy if recipient mares are provided. ET may be performed at considerably lower cost if the owner of the donor mare provides the recipient mare(s) and all horses are maintained at the farm of the donor mare owner.

\section{Embryo Recovery Procedure}

Embryo recovery is usually attempted 7 or 8 days post ovulation. We prefer to collect embryos on the afternoon of day 7 
or the morning of day 8 for the following reasons: 1) embryo recovery rate is high, 2) a majority of embryos are expanded blastocysts and are easily observed under the microscope, 3) occasionally, morula-stage embryos are recovered from some mares (typically older mares or mares bred with frozen semen) during that time period; those embryos may not be in the uterus on day 6 or early on day 7, and 4) embryos recovered later (i.e. day 9) are often too large to be handled without damaging the embryo.

Techniques for embryo recovery have not changed significantly in recent years. A sterile silicone catheter, typically 8.0 $\mathrm{mm}$ internal diameter, with an inflatable cuff is used to facilitate transcervical lavage. A $75 \mu \mathrm{m}$ in-line filter is either attached to the outflow line or the outflow line is manually regulated at the level of the filter (Fig. 1). There has been a change in the type of media used to flush donor mares over the past several years. Historically, many facilities made their own media from bulk chemicals and added antibiotics and fetal or newborn calf serum as a protein source. This was followed by the use of commercially prepared Dulbecco's phosphate buffered saline (PBS) to which antibiotics and lyophilized fetal calf serum was added. The ET industry in the United States has now largely shifted to the use of commercially prepared 'complete' flush media (non-PBS) that utilizes a Zwitterionbased buffer system and contains antibiotics and purified albumen (e.g. EquiPro ${ }^{T M}$ Recovery, Minitube of America, Verona, WI, EmCare ${ }^{T M}$, ICP, Auckland, NZ or ViGro ${ }^{T M}, A B$ Technology Inc., Pullman, WA). Lactated Ringer's solution (LRS) is not commonly used as an embryo flush media as yet. However, it is recognized that LRS has been used in other countries (i.e. Argentina and Brazil) for many years. Embryo collection rates and pregnancy rates following transfer have been good as long as holding times in this media is limited to less than one hour. It is predicted that the use of LRS may increase if costs of complete flush media increases.

The uterus of the donor mare is lavaged three to four times with $1-2$ liters aliquots of prewarmed $\left(30-35^{\circ} \mathrm{C}\right.$ ) embryo flush medium each time. The amount of fluid used for each flush is dependent on the size of the uterus. The goal is to expand the endometrium enough to allow fluid to effectively reach all parts of the endometrium, including the area between the endometrial folds. The mare often becomes mildly uncomfortable upon stretching of the perimetrium, and this can be used to indicate that sufficient infusion of fluid into the uterus has occurred. The flush medium is then allowed to flow back out the catheter by gravity flow through the embryo filter. The uterus of the mare is usually massaged per rectum during the infusion and recovery of the final liter of media. Complete recovery of the uterine lavage fluid is monitored by collecting the fluid in a graduated cylinder, and/or ultrasonographic examination of the uterus at the end of the procedure.

The search for an embryo may begin after each successive lavage or after the final liter of media is recovered. Contents of the filter are poured into a search dish and examined for the presence of an embryo. Recovered embryos are 'washed' by transferring them sequentially through several drops of holding medium. The embryo is graded for quality, measured and held in this medium until transferred.

If an embryo is not recovered following the initial series of lavages, additional media can be infused and 20 units of oxytocin administered intravenously. The media is allowed to stay in the mare for approximately 3 minutes before being allowed to exit by gravity flow aided by uterine massage per rectum.
In 2002 and the first 5 months of 2003, a total of 189 embryo recovery attempts were performed at CSU on client owned mares. Embryos were recovered on the first set of flushes ( 3 rounds of infusion using a total of 4 liters of media) on $31.2 \%$ of attempts. A total of 28 embryos were subsequently recovered during the 'extra' flush attempt when no embryo was recovered during the first series of flushes. Therefore, the final embryo recovery rate $(87 / 189)$ was $46.0 \%$. The increase in embryo recovery rate is economically very significant in a clinical ET program. It is recognized that there were differences in technique during the 'extra' flush procedure in that the medium was allowed to remain in the uterus for several minutes (Hinrichs 1990) and that oxytocin was used to stimulate uterine contractions. The point to be emphasized is that one should not give up if an embryo is not recovered on the first series of flushes. The cost of the additional media, oxytocin and clinician time is usually minimal compared with the potential value of a recovered embryo.

Fig 1 Non-surgical embryo collection procedure. (Illustrated by B. Lindsey, Minitube of America, Verona, WI).

Durchführung der unblutigen Embryo-Gewinnung (gezeichnet von B. Lindsey, Minitube of America, Verona, WI).

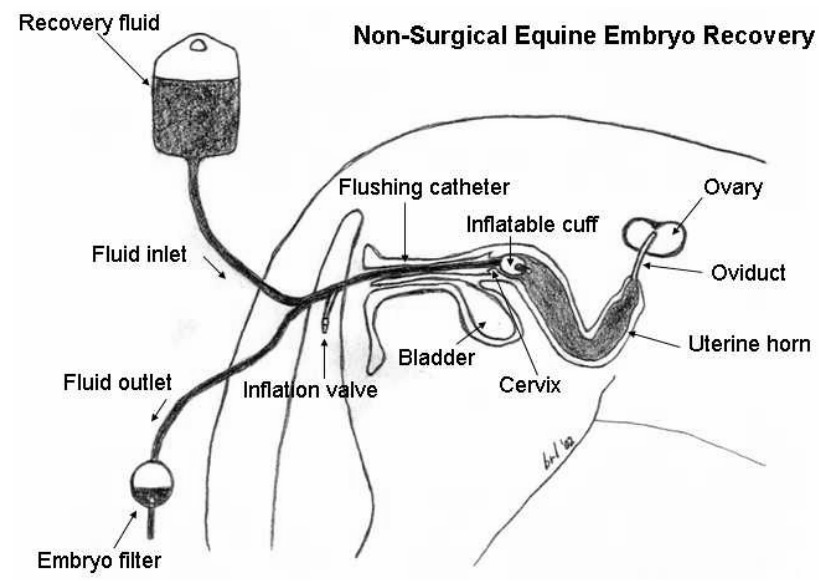

Embryo recovery rate is influenced by many factors, such as age and fertility of the donor mare, quality of the sire's semen, day of recovery, number of ovulations and clinical expertise. A higher percentage of embryos are recovered from mares less than 10 years of age compared to mares greater than 15 years of age. Embryo recovery rates appear to be approximately $5-10 \%$ below expected pregnancy rates per cycle (Morris and Allen 2001).

\section{Recipient Management and Selection}

Mares intended to be embryo recipients are usually purchased in the late fall, winter or early spring. A common trend now is to lease recipient mares from a horse broker. Mares not used or not pregnant at the end of the breeding season are returned.

Recipient mares range in age from 3 to 10 years. Since owners of donor mares often wish to begin embryo transfers in February or March, ET recipient mares are commonly placed under lights in early December to advance the onset of the first ovulation of the year. If cycling embryo recipients are not available in the early spring, transitional mares (Lagneaux and Palmer 1993) or ovariectomized mares (McKinnon et al. 
1988) can be administered exogenous progesterone and serve as a recipient. However, pregnancy rates for embryos transferred into progesterone treated transitional mares are somewhat lower than pregnancy rates for embryos transferred into cycling mares.

A donor embryo can be successfully transferred into a recipient mare that ovulates the day prior to $(+1)$, the same day (0) or up to 3 days (-3) after the donor mare. If a limited number of recipients are available, an individual recipient must be synchronized with each donor mare. Most big embryo transfer programs maintain large numbers of recipients and consequently have several mares ovulating on any given day. Synchronization of an individual donor and recipient mare is often requested by owners, but is discouraged. If necessary, it is recommended that 2 to 3 recipients be synchronized along with the donor in order to have at least one recipient mare ovulating during the critical time window. Ideally, the recipient mare would have ovulated 1-2 days after the donor mare.

Success of an embryo transfer program is highly dependent on the quality of recipient mares. Potential recipients are evaluated 5 days after ovulation to determine if they qualify to receive an embryo that cycle. Criteria used for evaluation include palpation and ultrasonography of the reproductive tract per rectum and occasionally analysis of blood progesterone concentrations. Mares are examined for tone in the uterus and cervix, presence of a corpus luteum on ultrasonography and an absence of endometrial folds (edema) or free fluid within the uterine lumen. Mares that 'pass' this examination are available for use as recipients for the next 2-3 days. Mares are rejected as potential recipients if poor uterine or cervical tone, a small (or absent) corpus luteum, endometrial edema or uterine fluid are detected. Serum progesterone concentrations can be measured if corpus luteum function is in doubt.

\section{Transfer Procedures and Success Rate}

Transfer of embryos into synchronized recipient mares can be performed surgically or non-surgically. Non-surgical transfer is preferred at most embryo transfer centers in the US. Most clinicians use similar techniques and premedications (if any). Recipient mares are usually administered acepromazine (20 $\mathrm{mg})$ and flunixin meglumine $(500 \mathrm{mg})$ intravenously 5-10 minutes prior to nonsurgical transfer. Additional medications such as systemic antibiotics, corticosteroids and other drugs are administered at some facilities (Foss et al. 1999). Administration of exogenous progesterone to recipient mares following ET is routinely performed at some facilities and not at all at others. Mares may receive either altrenogest 10.044 $\mathrm{mg} / \mathrm{kg}$ ) orally once daily for 60-120 days or may receive $1.500 \mathrm{mg}$ of a long-acting progesterone (BET Reproductive Laboratories, Inc., Lexington, KY) once every 7 days. The long-acting progesterone product has been shown in a controlled clinical trial to maintain pregnancies in mares in the absence of endogenous progesterone support (Vanderwall et al., unpublished data).

Embryos less than $1.000 \mu \mathrm{m}$ in diameter are typically transferred using a $0.25 \mathrm{ml}$ straw, disposable sterile sheath and stainless steel Cassou gun (IMV International Corp, Minneapolis, MN). Embryos greater than $1.000 \mu \mathrm{m}$ in diameter are transferred using a standard artificial insemination pipette. In both instances, a sterile outer chemise is used to protect the transfer gun or pipette from contamination with bacteria from the vulva, vestibule or vagina. Observations made by the authors and personnel at other specialized ET facilities using the Cassou gun system indicate that embryos may occasionally become caught in the side ejecting stainless steel tip of the disposable sheath. Consequently, one should rinse the tip of the sheath with media into a search dish after each transfer and examine the rinse fluid under a microscope. Embryos recovered following rinsing of the tip have been transferred (again) into the same recipient mare and have resulted in pregnancies. It should not be presumed that an embryo has been safely transferred into a recipient until the transfer gun has been examined.

Factors affecting transfer success include embryo quality, age of the donor mare, transfer technique, recipient quality and synchrony of the recipient (Squires et al. 1999). Pregnancy rate for 224 Grade 1 embryos transferred surgically at CSU in 1999 was $71.8 \%$. Pregnancy rate at day 16 for 480 grade 1 or 2 embryos transferred nonsurgically between 2000 and 2003 was $69.8 \%$.

\section{Superovulation}

Induction of multiple ovulations has been an elusive goal in the mare. Superovulation would potentially increase the efficiency and decrease the cost of embryo transfer by increasing embryo collection rates (McCue 1996, Squires et al. 2003). Unfortunately, techniques successful to superovulate ruminants, such as administration of porcine follicle stimulating hormone $(\mathrm{pFSH})$ and equine chorionic gonadotropin (eCG) have little effect in the mare. The most effective and consistent therapy to induce multiple ovulations in mares has been administration of equine pituitary gonadotropins (Douglas et al. 1974; Woods and Ginther 1983; Dippert et al. 1992). However, equine pituitary extract (EPE) is not commercially available. Recently a highly purified equine FSH product (eFSH; Bioniche Animal Health USA, Inc., Athens, GA) has become available commercially. Efficacy of eFSH to induce multiple ovulations in cycling mares was tested in 2002 and 2003. In the first study, 49 cycling mares were divided into 4 treatment groups. Group 1 mares served as untreated controls, while Group 2 mares were administered $25 \mathrm{mg}$ of eFSH intramuscularly twice daily beginning 5-6 days after ovulation. Prostaglandins were administered on the second day of treatment. Mares in Groups 3 and 4 received $12 \mathrm{mg}$ of eFSH using the same treatment regime. Mares in Groups 1, 2 and 4 were administered a GnRH agonist, deslorelin to induce ovulation while mares in Group 3 were administered hCG to induce ovulation. Mares were bred with frozen semen and examined for pregnancy 12, 14 and 16 days after ovulation. The most effective treatment regimen in terms of ovulation rate (3.4 \pm 0.7 ovulations per cycle) and pregnancy rate (1.8 \pm 0.8 embryonic vesicles per mare) was for the group administered $12 \mathrm{mg}$ eFSH and induced to ovulate with hCG (Niswender et al., unpublished data). A follow up study was conducted in Brazil using the same eFSH product at the $12 \mathrm{mg}$ dose. In that study, mares were bred with fresh semen and an embryo collection attempt was performed 7 days postovulation. The ovulation rate and embryo recovery rate for eFSH treated mares $(3.6 \pm 0.5$ ovulations per cycle and $1.9 \pm 0.3$ embryos recovered per cycle) were significantly higher than rates in control mares (1.0 \pm 0.0 ovulations per cycle and $0.5 \pm 0.1$ embryos recovered per cycle). In both studies approximately 7 to 8 days of eFSH treatment were required to 
stimulate multiple large follicles to develop to the point that hCG could be administered. Equine FSH has been used extensively in the United States during the 2003-breeding season to induce multiple ovulations for the purpose of embryo transfer.

\section{Transported Embryos}

The use of embryo transfer in the US has become more popular as technology that allows for short-term storage and transportation of equine embryos has become available (Carnevale et al. 1987). Cooled-transported embryo programs have made embryo transfer available to horse owners that do not want to ship a donor mare to a referral center. The media used for shipping embryos has traditionally been Ham's F-10 bubbled with $5 \% \mathrm{O}_{2}, 5 \% \mathrm{CO}_{2}$ and $90 \% \mathrm{~N}_{2}$ and supplemented with calf serum and antibiotics. The main problem with Ham's F-10 is the requirement for gassing and the limited shelf life once prepared. Consequently, a clinic or farm must prepare their own Ham's F-10 if an embryo is recovered or the media needs to be prepared by the referral center and shipped by overnight delivery service or counter-to-counter airline service to the collection site in anticipation of a successful embryo collection attempt. Unfortunately, embryos are retrieved on $<50 \%$ of attempts, so the time and expense of preparing and shipping the media is wasted on many occasions.

New holding media for cooled transported embryos have been developed. These holding media are zwitterionic buffered solutions, with nutrients, growth factors, amino acids, and BSA added to the solution. The composition of the media allows the embryo to survive for an extended time. Research and clinical data collected over the past 2-3 years has suggested that alternative media, such as EmCare ${ }^{T M}$ Embryo Holding Solution or ViGro ${ }^{T M}$ Holding Plus, that do not require gassing may be used successfully for short-term storage and shipment of equine embryos (McCue et al. 2000; Moussa et al. 2002). Several major embryo transfer clinics in the United States currently use this type of holding solutions exclusively for shipping embryos. The media and associated shipping supplies are sent to the farm or embryo collection facility at the beginning of the breeding season. If an embryo is recovered it is packaged in a small $(5 \mathrm{ml})$ plastic tube filled with holding media. The small tube containing the embryo is placed within a larger $(50 \mathrm{ml})$ conical tube filled with either flush or holding media. Both tubes are sealed with parafilm strips and placed into a passive cooling system (Equitainer ${ }^{\circledR}$, Hamilton-Thorne Biosciences, Beverly, MA). In most instances, embryos maintained in holding solutions are shipped by counter-to-counter airline service and the embryo is transferred into a synchronized recipient within 12 to 16 hours of recovery.

\section{Embryo Freezing}

The first successful term pregnancy from a frozen-thawed equine embryo was reported in 1982 (Yamamoto et al. 1982). In general, smaller embryos collected 6 days after ovulation survive the freezing and thawing procedures better than day-7 or day-8 embryos (Seidel 1996). Recent reports by Lascombes and Pashen (2000) and Maclellan et al. (2002) have indicated that transfer success rate after thawing of small equine embryos can reach levels acceptable for com- mercial use. Maclellan et al. (2002) noted a pregnancy rate of $70.6 \%$ (12 of 17) following transfer of frozen-thawed embryos $<300 \mu \mathrm{m}$ in diameter and $70.0 \%$ (14/20) for nonfrozen control embryos. Frozen equine embryos are being advertised for sale on the internet.

There has been an increased interest in embryo freezing in the equine breeding industry in the United States in the past year. The two most likely scenarios by which embryo freezing will play a role in the near future are: 1) 'extra' embryos collected from superovulated mares for which no recipient is available will be frozen and transferred when a suitable recipient becomes available and 2) valuable mares will be superovulated and bred in the off season (mid-July to the end of September) and embryos will be frozen and transferred the following Spring.

\section{Literature}

Carnevale E. M., Squires E. L. and McKinnon A. O. (1987): Comparison of Ham's F-10 with $\mathrm{CO}_{2}$ or Hepes buffer for the 24-hour storage of equine embryos at $5^{\circ} \mathrm{C}$. J Anim Sci 65, 1775-1781

Dippert K. D., Hofferer S., Palmer E., Jasko D. J. and Squires E. L. (1992): Initiation of superovulation in mares 5 or 12 days after ovulation using equine pituitary extract with or without $\mathrm{GnRH}$ analogue. Theriogenology 38, 695710

Douglas R. H., Nuti L. and Ginther O. J. (1974): Induction of ovulation and multiple ovulation in seasonally anovulatory mares with equine pituitary fractions. Theriogenology 2, 133-142

Foss R., Wirth N., Schiltz P. and Jones N. (1999): Nonsurgical embryo transfer in a private practice (1998). Am Assoc Equine Pract 45, 210-212

Hinrichs K. (1990): A simple technique that may improve the rate of embryo recovery on uterine flushing in mares. Theriogenology 33, 937-942

Lagneaux D. and Palmer E. (1993): Embryo transfer in anestrous recipient mares: attempts to reduce altrenogest administration period by treatment with pituitary extract. Equine Vet J 15(suppl), 107-111

Lascombes F. A. and Pashen R. L. (2000) Results from embryo freezing and post ovulation insemination in a commercial embryo transfer programme. Proc $5^{\text {th }}$ International Symposium on Equine Embryo Transfer, Saari, Finland, July, 2000

Maclellan L. J., Carnevale E. M., Coutinho da Silva M. A., McCue P.M., Seidel Jr. G. E. and Squires E. L. (2002): Cryopreservation of small and large equine embryos pre-treated with cytochalasin-B and/or trypsin. Theriogenology 58, 717-720

McCue P. M. (1996): Superovulation. Vet Clinics North America: Equine Practice 12, 1-11

McCue P. M., Scoggin C. F., Meira C. and Squires E. L. (2000): Pregnancy rates for equine embryos cooled for 24 hours in Ham's F-10 vs. emcare ${ }^{T M}$ embryo holding solution. Proc Ann Conf Soc for Theriogenology p. 147

McKinnon A. O., Squires E. L., Carnevale E. M. and Hermenet M. J. (1988): Ovariectomized, steroid-treated mares as embryo recipients and as a model to study the role of progestins in pregnancy maintenance. Theriogenology 29, 1055-1063

Morris L. H. A. and Allen W. R. (2001): Reproductive efficiency of intensively managed Thoroughbred mares in Newmarket. Pferdeheilkunde 17, 548556

Moussa M., Duchamp G., Mahla R., Bruyas J.-F. and Daels P. F. (2002): Comparison of pregnancy rates for equine embryos cooled for $24 \mathrm{~h}$ in Ham's F10 and emcare holding solutions. Theriogenology 58, 755-757

Seidel, G.E. (1996) Cryopreservation of equine embryos. Vet Clin North Amer: Eq Pract 12, 85-99.

Squires E. L., Carnevale E. M., McCue P. M. and Bruemmer J. E. (2003): Embryo technologies in the horse. Theriogenology 59, 151-170

Squires E. L., McCue P. M. and Vanderwall D. (1999): The current status of equine embryo transfer. Theriogenology 51, 91-104

Woods G. L. and Ginther O. J. (1983): Induction of multiple ovulations during the ovulatory season in mares. Theriogenology 20, 347-355

Yamamoto Y., Oguri N., Tsutsumi Y. and Hachinohe Y. (1982) Experiments in freezing and storage of equine embryos. J Repr Fert 32(suppl), 399-403

Dr. Patrick M. McCue

Colorado State University

Equine Reproduction Laboratory

Fort Collins, CO 80523, USA

pmccue@colostate.edu 